OPEN ACCESS

Edited by:

Marco Lucchi,

University of Pisa, Italy

Reviewed by: Michelangelo Maestri,

University of Pisa, Italy

Yu Hong,

University of Bergen, Norway

Yun Wang,

Sichuan University, China

${ }^{*}$ Correspondence:

Ewa Wrona

ewawrona00@gmail.com

Specialty section: This article was submitted to Autoimmune and Autoinflammatory Disorders, a section of the journal

Frontiers in Immunology

Received: 17 July 2020 Accepted: 12 April 2021 Published: 29 April 2021

Citation:

Wrona E, Dębska-Szmich S, Pastuszka M, Braun M, Czyżykowski R and Potemski P (2021) Remission of Thymoma on Steroid Therapy in a

Patient With Atypical ThymomaAssociated Multiorgan Autoimmunity: A Case Report and Literature Review.

Front. Immunol. 12:584703. doi: 10.3389/fimmu.2021.584703

\section{Remission of Thymoma on Steroid Therapy in a Patient With Atypical Thymoma-Associated Multiorgan Autoimmunity: A Case Report and Literature Review}

\author{
Ewa Wrona ${ }^{1 *}$, Sylwia Dębska-Szmich ${ }^{1}$, Marta Pastuszka $^{2}$, Marcin Braun $^{3}$, \\ Rafał Czyżykowski ${ }^{1}$ and Piotr Potemski ${ }^{1}$ \\ 1 Department of Chemotherapy, Copernicus Memorial Hospital in Lodz, Medical University of Lodz, Lodz, Poland, \\ 2 Department of Dermatology, Medical University of Lodz, Lodz, Poland, ${ }^{3}$ Department of Pathology, Chair of Oncology, \\ Medical University of Lodz, Lodz, Poland
}

In up to $34 \%$ of cases, thymoma, itself a rare neoplasm, is accompanied by autoimmune disorders, two of which are thymoma-associated multiorgan autoimmunity (TAMA) and paraneoplastic autoimmune multiorgan syndrome (PAMS). Unfortunately, differential diagnosis between these two entities can be challenging since no strict PAMS definition exists and PAMS can overlap with a subgroup of TAMA patients with skin lesions as leading presentation. We present a case of a 68-year-old woman with a diagnosis of thymoma accompanied by myasthenia gravis, hypothyroidism and GvHD-like mucocutaneous lesions that initially could account to both TAMA and PAMS diagnosis. However, following the exclusion of humoral autoimmunity against components of epithelial cells junction, TAMA was finally established. Interestingly, the introduction of corticosteroid therapy for TAMA symptom management resulted in unexpected partial remission of thymoma with no impact on mucocutaneous lesions. Our case study is an example of two extremely rare phenomena accompanying thymomas: unprecedented TAMA presentation with GVHD-like mucositis, which as we postulate should be placed in the spectrum of TAMA, and tumor remission on steroids.

Keywords: thymoma, thymoma-associated multiorgan autoimmunity (TAMA), paraneoplastic autoimmune multiorgan syndrome (PAMS), mucocutaneous lesions, remission on steroids

\section{INTRODUCTION}

Thymoma is described as a rare neoplasm that constitutes roughly $0.2 \%$ to $1.5 \%$ of all malignancies, with an annual age-standardized incidence rate of 0.13 cases per 100000 population (1). Up to $34 \%$ of thymomas are thought to be accompanied by symptoms of autoimmunity (2). Based on previous reports, the most frequently described ones are myasthenia gravis (MG) (96.5\%), pure red blood cell aplasia (PRCA) (2.2\%) and hypogammaglobulinemia (0.6\%); while panencephalitis, enterocolitis, autoimmune hepatitis and erythematous dermatitis are incidentally described in the literature 
(2-7). The autoimmune reactions that accompany thymoma have a number of possible targets, resulting in a wide range of symptoms; in addition, as the patients demonstrate high heterogeneity there is great disagreement on how to classify these rare cases.

The term 'thymoma-associated multiorgan autoimmunity' (TAMA) emerged in 2007 to describe patients with Graftversus-Host Disease-like (GvHD-like) dermatitis, enterocolitis or hepatitis with underlying thymoma and no prior haematopoietic stem cell (HSCT) nor organ transplantation (8). This contrasted with the term 'paraneoplastic autoimmune multiorgan syndrome' (PAMS), which was proposed in 2001 for cases characterized by mucocutaneous lesions often extending to the aerodigestive tract with bronchial involvement, humoral autoimmunity against cellular adhesion molecules, poor response to treatment and high mortality rate $(9,10)$. TAMA criteria may apply more closely to a narrow, well-distinguished group of thymoma patients, currently represented by only 31 published cases; however, PAMS is much broader and has a distorted definition and its diagnostic PAMS criteria can partially overlap with patients suspected of TAMA with predominant dermatitis (Supplementary Table 1). Moreover, several groups postulate TAMA, as well as paraneoplastic pemphigus to be a variation of PAMS, however this opinion is not widely approved $(11,12)$.

We report a case of a patient diagnosed with locally-advanced thymoma accompanied by MG, hypothyroidism, slowly progressing mucocutaneous lesions of mild intensity with histopathology features classified as GvHD-like, and neither humoral autoimmunity nor bronchial involvement. The article describes the extensive diagnostic process employed to resolve a lack of consensus on how to properly distinguish TAMA from PAMS, two extremely rare entities. Strikingly, the use of corticosteroid therapy, as a treatment of persistent mucocutaneous lesions, resulted in partial remission of thymoma with no improvement of skin or oral cavity condition. Which altogether led us to transfer the discussion on our patient to a wider audience.

\section{CASE DESCRIPTION}

A 68-year-old Caucasian woman with an initial diagnosis of thymoma was admitted to the Department of Chemotherapy in November 2018 for an evaluation and treatment implementation. On admission, she reported a sixmonth history of poor appetite, weight loss of $12 \mathrm{~kg}$ (24\% of initial body weight), generalized fatigue, muscle weakness, oral cavity lesions resembling candidiasis that persist despite antifungal therapy, erythematous scaly papules affecting skin surrounding her nose, mouth and buttocks, as well as the distal parts of the upper extremities and palms, with concomitant degeneration of the finger nail plates (Figure 1A). No chest pain, cough, dyspnea or diarrhea was reported, and no signs of phrenic nerve palsy were observed. No relevant family history was reported. The patient suffered from hypertension, otherwise healthy. Her performance status (PS) according to Eastern Cooperative Oncology Group (ECOG) was assessed as 4 , mostly due to severe muscle weakness. Computed tomography (CT) revealed a locally advanced tumor $(64 \times 30$ $\mathrm{x} 76 \mathrm{~mm}$ ) in the upper part of the anterior mediastinum with suspected infiltration of superior vena cava (VCS); no signs of distant metastases nor lymph node involvement were observed (Figure 2A). Histopathology examination revealed WHO type B1 thymoma with immunophenotype: AE1/AE3+, BCL6 -/+, CD20-, CD23-, CD3+, CD5+, cyclin D1-, p53 -, Ki67 high. The disease was assessed as stage III according to Masaoka-Konga and as rT3N0M0 according to IASCL/ITMIG.

\section{DIAGNOSTIC ASSESSMENT}

\section{Autoimmunity Management}

The patient's complete blood count, liver and kidney function profiles on admission were within normal limits. Neither hypogammaglobulinemia nor pure red blood cell aplasia were suspected. The patient's thyroid profile normalized gradually on levothyroxine sodium (75 $\mu \mathrm{g}$ once daily) supplementation and Hashimoto thyroiditis, as a cause of primary hypothyroidism, was ruled out (GH, PRL levels were within normal limits, antiTPO and anti-TG antibodies were negative). Additionally, MG diagnosis was confirmed based on the presence of anti-AchR antibodies (196 nmol/l in RIA assay) with a lack of anti-MuSK antibodies $(<0.03 \mathrm{nmol} / \mathrm{l}$ in RIA assay). Muscle weakness gradually resolved upon pyridostigmine bromide treatment $(60$ mg three times a day) and physical therapy.

\section{Thymoma Treatment}

Taking into consideration the patient's poor performance status (resulting mainly from uncontrolled $\mathrm{MG}$ and hypothyroidism symptoms) and cachexia, the treatment plan involved reduced dose chemotherapy, symptom control and physical therapy while thymectomy and radical radiotherapy were contraindicated due to VCS infiltration. First-line PE combination chemotherapy (cisplatin $60 \mathrm{mg} / \mathrm{m} 2$, etoposide 75 $\mathrm{mg} / \mathrm{m} 2$ day 1 to 3 for 6 cycles every 3 weeks) was launched with $20 \%$ dose reduction only during the first cycle. Chemotherapy was well tolerated, with no severe adverse events ( $\geq$ Grade 3 according to Common Terminology Criteria for Adverse Events (CTCAE) version 5.0).

During the systemic treatment, symptoms mitigated and patient's condition gradually improved, however with no signs of reduction of mucocutaneous lesions (Figure 1B). A CT scan after six cycles of chemotherapy showed that the longest diameter of the tumor slightly decreased from $76 \mathrm{~mm}$ to $70 \mathrm{~mm}$ (Figure 2B). Despite demonstrating significant clinical improvement (PS1 - marginal muscle weakness, persistent mucocutaneous lesions) and achieving stable disease (SD) according to Response Evaluation Criteria in Solid Tumors (RECIST) 1.1 criteria, neither thymectomy nor radical radiotherapy were advised due to persistent VCS involvement. 
A

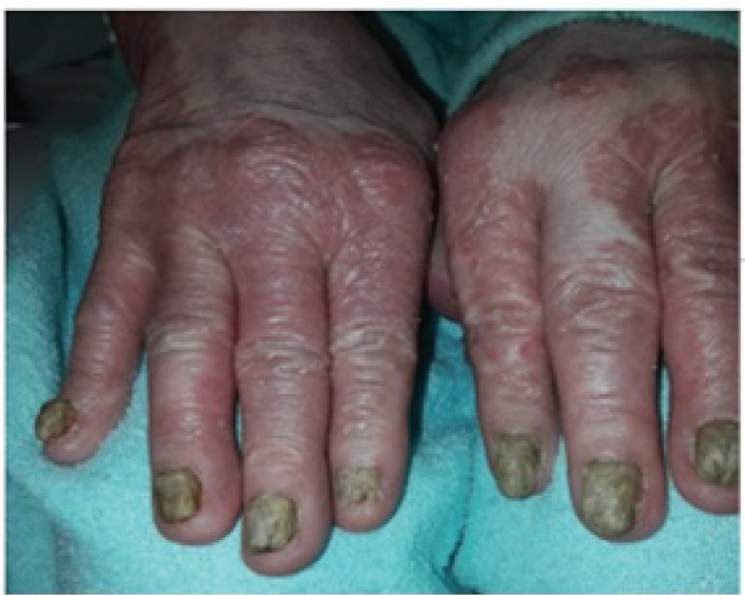

B

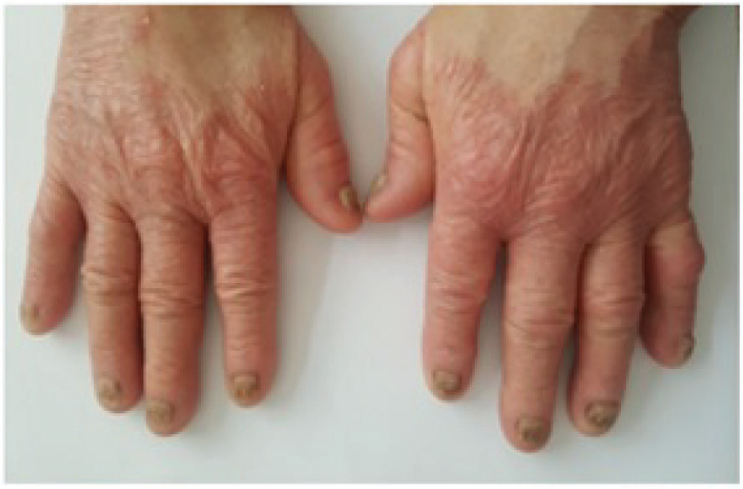

C

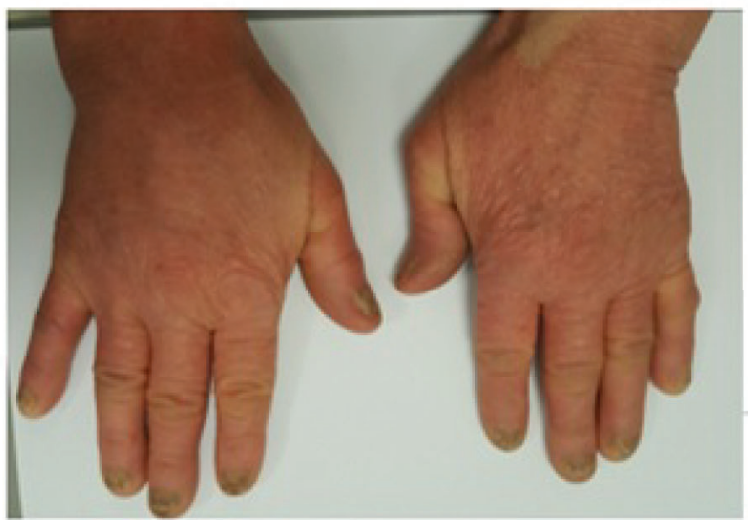

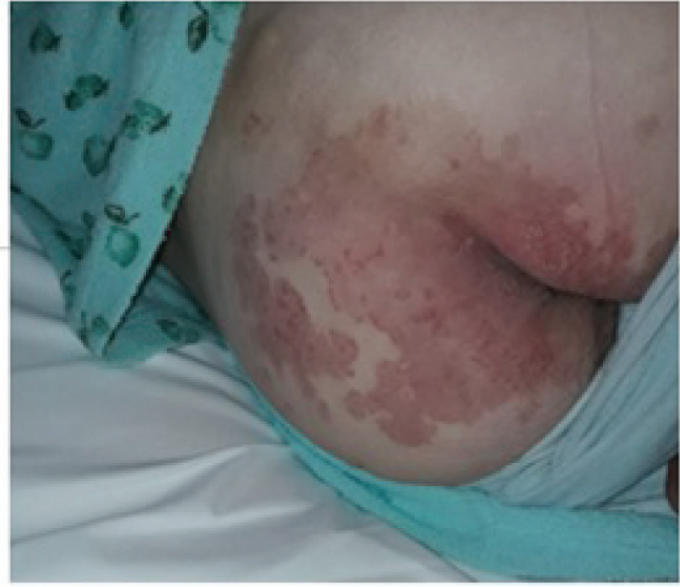
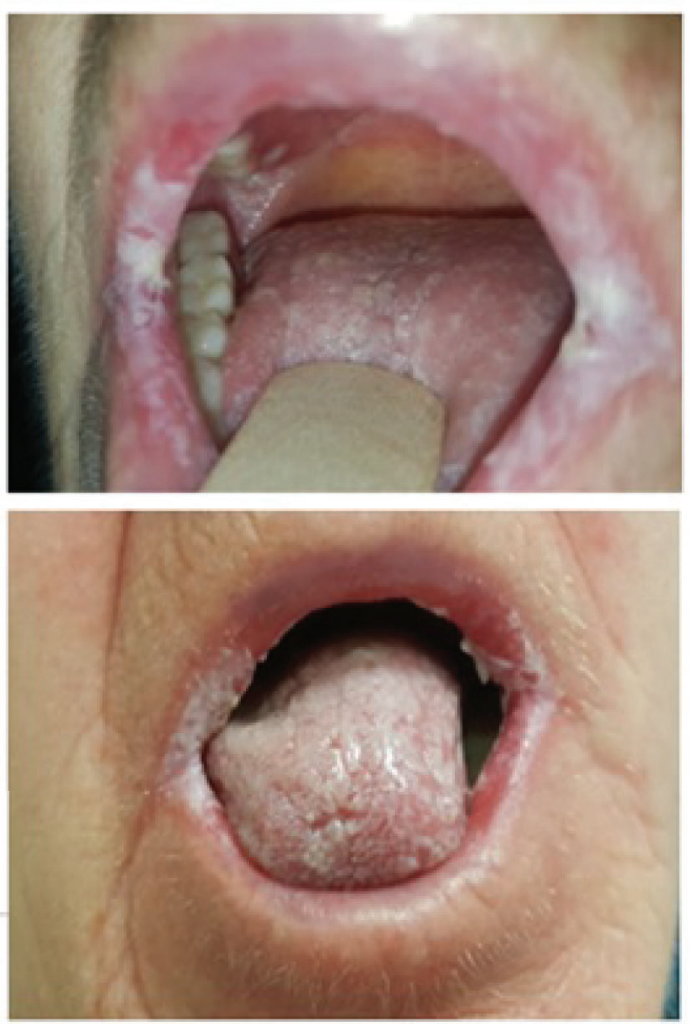

FIGURE 1 | TAMA. Skin and mucosal lesions photographed (A) at the onset of chemotherapy, (B) after six cycles of systemic treatment and (C) after three months of prednisone therapy.

\section{Skin and Oral Mucosa Lesions}

To diagnose the mucocutaneous lesions, surgical samples of affected tissues were obtained. Based on histopathological features, immunohistochemistry and clinical data, various GvHD-like changes were observed in the skin: parakeratosis, dyskeratosis, intensive basal layer destruction, intracellular oedema, subepidermal atypic lymphocyte $\mathrm{T}$ infiltration without features of malignancy (CD3+, CD4+>CD8+ at a ratio of 1.5-2:0, incidental $\mathrm{CD} 30+$ ), and focal destruction of skin appendages (Figure 3A) despite the lack of HSCT or organ transplantation in the patient's past medical history. Correspondingly, GvHD-like changes were also reported in the oral mucosa sample: intensive T-cell infiltration $(\mathrm{CD} 3+, \mathrm{CD} 4+>\mathrm{CD} 8+$ at a lower ratio than in skin sample, incidental B-cell lymphocytes), basal layer destruction, acanthosis, hyperkeratosis (Figure 3B). Blood serum evaluation was negative for RF, anti-CCP, anti-Ro, antiLa and anti-dsDNA and weakly positive for anti-Sm antibodies.

Based on the test results and clinical presentation, a strong suspicion of TAMA was raised. However, due to the fact that diagnostic criteria for TAMA and PAMS overlap for patients 
A
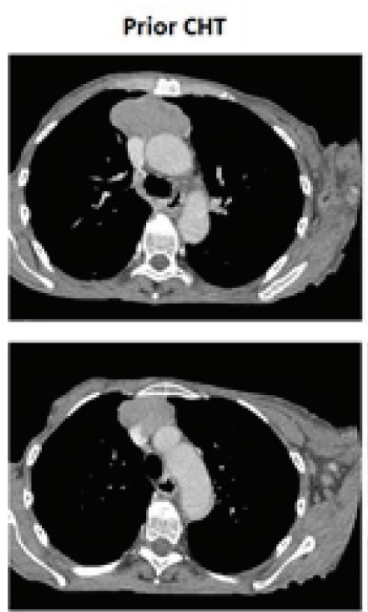
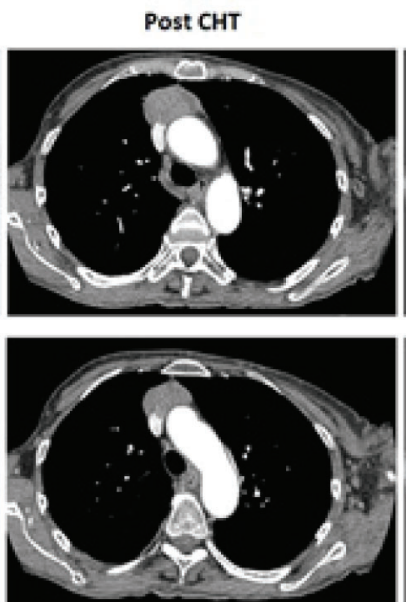
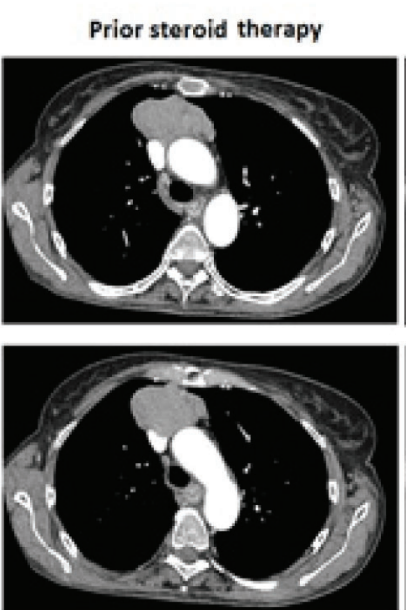
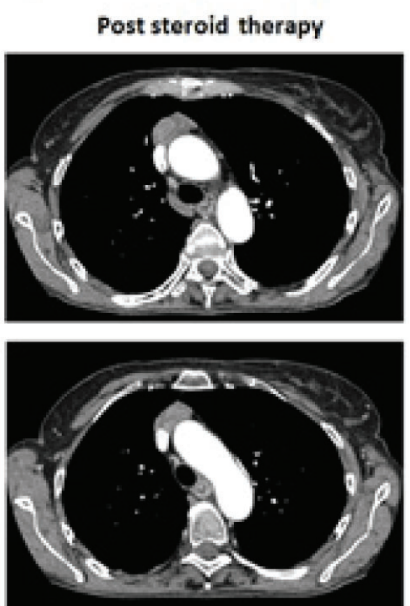

FIGURE 2 | Thymoma. Computer tomography imaging showing maximal tumor dimensions (upper row) and infiltration on VCS (bottom row): (A) prior systemic treatment (64 x 30 × 76 mm); (B) after completion of chemotherapy (51 x 26 × 70 mm); (C) prior corticosteroids implementation (65x63×75mm); (D) after three months of corticosteroid therapy (30x17mm).
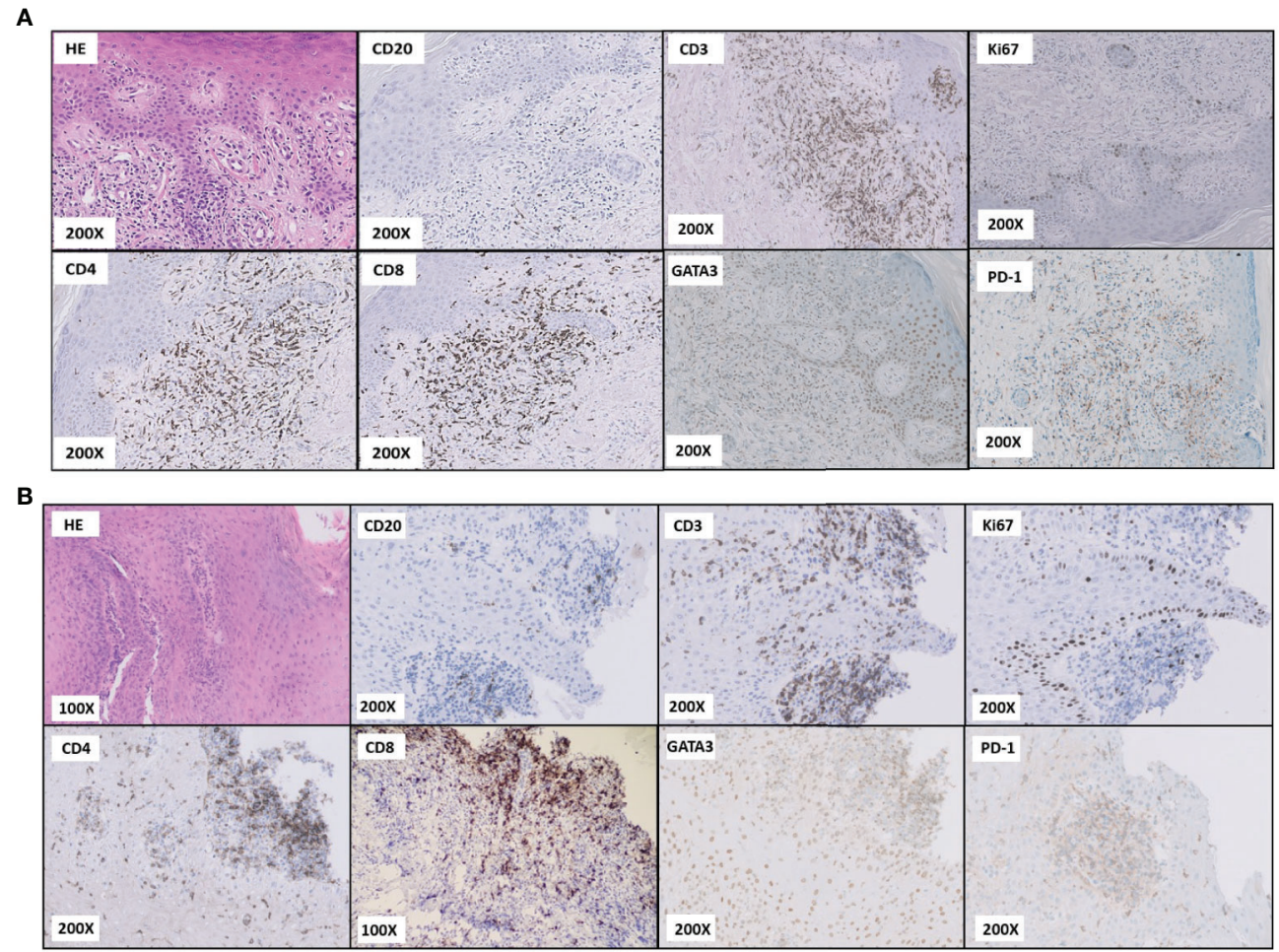

FIGURE 3 | TAMA. HE and immunostaining of the skin (A) and oral mucosa (B) samples in magnification.

with the GvHD-like dermatitis, and that mucosal involvement was found to be more characteristic of PAMS, the differential diagnosis was broadened. An analysis of humoral autoimmunity against epithelial cells junction components was performed
(Supplementary Table 1). Ultimately, the skin and blood samples tested negative in direct immunofluorescence (DIF) for IgG, IgM, IgA and C3 deposits, and negative in indirect immunofluorescence (IIF) on a rat urinary bladder. In addition, 
the patient was negative for antibodies against desmoglein 1, desmoglein 3, BP 180, BP 230, envoplakin and collagen type VII (all equal or less than $0.1 \mathrm{RU} / \mathrm{ml}$, with cut-off $>1.0 \mathrm{RU} / \mathrm{ml}$ in ELISA assay); this definitively ruled out a diagnosis of PAMS. Therefore, seven months after chemotherapy completion, low dose prednisone $(0.5 \mathrm{mg} / \mathrm{kg}$ a day $)$ treatment was launched.

Unfortunately, neither skin nor mucosal lesions resolved after three months of low-dose prednisone therapy (Figure 1C); no other anti-cancer treatment was administered and dosing of 0.5 $\mathrm{mg} / \mathrm{kg}$ a day was not escalated due to poor tolerance. Quite unexpectedly, routine follow-up CT scan revealed good partial response (PR) of the upper-mediastinal mass, according to RECIST 1.1 criteria, with its measurements decreasing substantially to $30 \mathrm{~mm}$ from $75 \mathrm{~mm}$ prior to corticosteroid therapy, and the disappearance of VCS infiltration (Figures 2C, D).

Due to resolved VCS infiltration observed in the CT scan, radical thymectomy was advised; however, the patient refused the surgery. She has since been referred to the Department of Radiotherapy for irradiation of residual thymoma with $66 \mathrm{~Gy}$ (33 x 2 Gy). At the time of writing, the patient remained in PR (tumor measurements on the latest CT scan $30 \times 24 \mathrm{x}$ $38 \mathrm{~mm}$ ) with persistent mucocutaneous lesions, negligible muscle weakness, stable body weight and energy level. Due to poor tolerance (dizziness, headache, nausea), the dose of prednisone was decreased to $0.3 \mathrm{mg} / \mathrm{kg}$ a day with no deterioration of skin condition and no signs of thymoma progression. Levothyroxine, pyridostigmine and concomitant physical therapy were maintained. Detailed timeline on the patient's diagnostic process and treatment was presented in the Supplementary Figure 1.

\section{DISCUSSION}

Including the patient described in this article, only 32 cases of TAMA were found to have been published between 1995 and 2020 (8, 13-36). Twenty six patients presented with GvHD-like dermatitis, clinically manifested as erythematous scaly papules disseminated over the whole body (Table 1). Corticosteroid therapy, both oral and topical, caused skin lesion remission in twelve cases out of 19; while phototherapy was much more effective, but rarely applied (four remissions out of five described cases). Oral mucosa lesions, clinically demonstrated as erosions and ulcerations, were described only in four TAMA patients; however, no biopsy sample was obtained to determine their histological presentation.

In contrast to TAMA, where GvHD-like features are strictly required for diagnosis, PAMS demonstrated considerable symptom heterogeneity between patients, due to the variable manifestations of mucocutaneous lesions, e.g. pemphigus-like, bullous pemfigoid-like, erythema multiforme-like, GvHD-like and lichen planus-like forms (10). The uncertainty encountered during the presented diagnostic process resulted from the fact that GvHD-like dermatitis is common for both PAMS and TAMA. On the other hand, GvHD-like mucositis, typical for PAMS, was an undescribed but possible symptom in TAMA. Additionally, the mucocutaneous lesions did not improve in response to corticosteroid therapy; that stays in accordance with previous reports, where steroid therapy or palliative treatment of underlying neoplasm did not assure remission in TAMA, and only resulted in transient improvement in PAMS $(37,38)$. The present report is the first to discuss a patient with both an established TAMA diagnosis and GvHD-like mucositis. Hence, we suggest that GvHD-like mucositis should be placed in the spectrum of TAMA.

Scarce data exists on pathomechanisms of TAMA beyond the common background of cellular autoimmunity in thymoma e.g. errors in negative T-cells selection, decreased expression of autoimmune regulator - AIRE gene, overproduction of CD4+ and $\mathrm{CD} 8+$ single-positive and immature CD4+CD8+ doublepositive T-cells, decreased Treg number and decreased major histocompatibility complex (MHC) class II expression $(25,32$, 39, 40). Previous studies have found humoral reactions to predominate over cellular reactions in PAMS, and this is reflected in the diagnostic criteria. A few studies on PAMS have shown that tumors like thymoma, follicular dendritic cell sarcoma or B-cell lymphomas can secret antibodies against various proteins which could be a cornerstone in PAMS pathogenesis $(41,42)$. Hence, PAMS diagnosis requires an accumulation of antibodies in affected tissue; this can be confirmed by either DIF, positive rat bladder IIF, the presence of circulating antibodies directed mostly against plakin proteins family (desmoplakin 1, desmoplakin 2, envoplakin, periplakin) or against BP180, BP230, A2ML1. In contrary, expression of antibodies against desmoglein 1 and desmoglein 3 is characteristic rather of pemphigus vulgaris (PV), pemphigus foliaceus (PF) and paraneoplastic pemphigus (PNP) but not PAMS $(10,12,43)$. Nevertheless, up to $16 \%$ of PAMS patients do not express circulating antibodies in ELISA assay (44). In some of these cases, the role of BP180 specific CD4+T-cells was postulated as possible cellular mechanism of autoimmunity, especially in GvHD-like and lichen planus-like PAMS manifestations (45-47). Taking that in mind, serological tests for exclusion of PAMS, PNP, PV and PF should be considered while establishing TAMA diagnosis.

A literature search on EMBASE, MEDLINE, PubMed and Cochrane databases with the terms thymoma, remission and steroid identified only 26 reports of thymoma patients demonstrating objective responses to corticosteroid monotherapy since 1952 (48-61). Out of these cases, five were reported to have complete remissions, while only one received a CT reassessment (57) and the remaining four were followed-up with X-ray examination only $(48,49,56,61)$. Spectacular responses were thought to be caused by an impact of corticosteroids on lymphocytic component of the tumor however, a few remissions in mixed and epithelial dominant tumors were also described (58). In most cases, corticosteroids were launched as palliation or for managing autoimmunity symptoms, which was also an indication in the presented patient (in majority for myasthenia gravis control - 11 cases, incidentally syndrome of inappropriate antidiuretic hormone secretion (SIADH) and 
TABLE 1 | A summary of all known published cases described as Thymoma-associated multiorgan autoimmunity.

\begin{tabular}{|c|c|c|c|c|c|c|c|c|c|}
\hline $\begin{array}{l}\text { Pt } \\
\text { no. }\end{array}$ & $\begin{array}{l}\text { Age at } \\
\text { diagn. }\end{array}$ & Gender & $\begin{array}{l}\text { Thymoma } \\
\text { type/stage }\end{array}$ & Clinical symptoms & $\begin{array}{l}\text { Other thymoma } \\
\text { associated } \\
\text { autoimmunities }\end{array}$ & Diagnosis & TAMA treatment & Prognosis & Reference \\
\hline 1 & 50 & Male & IV & $\begin{array}{l}\text { Erythematous scaly rash of the } \\
\text { face, trunk, upper and lower } \\
\text { extremities, palms, feet, no } \\
\text { scalp or mucosal involvement } \\
\text { edema, diarrhea }\end{array}$ & Hypogammaglobulinemia & $\begin{array}{l}\text { GvHD-like changes in the skin } \\
\text { biopsy sample }\end{array}$ & $\begin{array}{l}\text { Steroids, topical } \\
\text { triamcinolone, } \\
\text { PUVA, IVIG }\end{array}$ & $\begin{array}{l}\text { PUVA was applied only few times, too little } \\
\text { to draw any conclusions. Died } 3 \text { years after } \\
\text { first TAMA symptoms due to sepsis. }\end{array}$ & $\begin{array}{l}\text { Wadhera } \\
\text { et al. (8) }\end{array}$ \\
\hline 2 & 20 & Male & B1, recurrent & Severe diarrhea, weight loss & - & $\begin{array}{l}\text { GvHD-like features in colon } \\
\text { biopsy sample }\end{array}$ & Steroids & $\begin{array}{c}\text { Several remissions of thymoma entailed by } \\
\text { TAMA symptoms resolving }\end{array}$ & $\begin{array}{l}\text { Kornacki } \\
\text { et al. (17) }\end{array}$ \\
\hline 3 & 38 & Female & IVa & $\begin{array}{l}\text { Erythematous morbiliform } \\
\text { eruption of the skin on trunk, } \\
\text { upper and lower extremities, } \\
\text { oral mucosa ulcerations, } \\
\text { abnormal LFTs, diarrhea }\end{array}$ & $\begin{array}{c}\text { MG, } \\
\text { hypogammaglobulinemia }\end{array}$ & $\begin{array}{l}\text { GvHD-like changes in the skin } \\
\text { and colon biopsy samples }\end{array}$ & Steroids & Died of diarrhea and respiratory infection & $\begin{array}{l}\text { Wang et al. } \\
\text { (13) }\end{array}$ \\
\hline 4 & 47 & Male & Al & $\begin{array}{l}\text { Pruritic morbiliform eruption on } \\
\text { face and trunk, mucosal } \\
\text { erosions, diarrhea }\end{array}$ & $\begin{array}{l}\text { Hypogammaglobulinemia, } \\
\text { PRCA }\end{array}$ & $\begin{array}{l}\text { GvHD-like changes in the skin } \\
\text { biopsy sample }\end{array}$ & $\begin{array}{l}\text { IVIG, cyclosporine } \\
\text { A }\end{array}$ & No data & $\begin{array}{l}\text { Holder } \\
\text { et al. (19) }\end{array}$ \\
\hline 5 & 35 & Female & IVa & $\begin{array}{c}\text { Morbilliform eruption on trunk, } \\
\text { diarrhea }\end{array}$ & MG & $\begin{array}{l}\text { GvHD-like changes in the skin, } \\
\text { duodenum and colon biopsy } \\
\text { sample }\end{array}$ & $\begin{array}{l}\text { Steroids, } \\
\text { cyclosporine A, } \\
\text { IVIG, octreotide (for } \\
\text { diarrhea) }\end{array}$ & $\begin{array}{l}\text { Partial improvement of skin lesions on } \\
\text { steroids. Diarrhea moderately improved on } \\
\text { octreotide. Died of thymoma progression }\end{array}$ & $\begin{array}{l}\text { Lowry et al. } \\
\qquad(16)\end{array}$ \\
\hline 6 & 46 & Male & IVa & Diarrhea & - & $\begin{array}{l}\text { GvHD-like changes in the } \\
\text { colon biopsy sample }\end{array}$ & Steroids & Persistent diarrhea & $\begin{array}{l}\text { Sader et al. } \\
\text { (31) }\end{array}$ \\
\hline 7 & 57 & Female & III & $\begin{array}{l}\text { Diarrhea, erythema-multiforme } \\
\text { resembling skin lesions, } \\
\text { abnormal LFTs }\end{array}$ & Hypogammaglobulinemia & $\begin{array}{l}\text { GvHD-like changes in the skin } \\
\text { biopsy sample }\end{array}$ & Steroids, IVIG & $\begin{array}{l}\text { Died of sepsis following complications of } \\
\text { thymectomy. }\end{array}$ & $\begin{array}{l}\text { Sleijfer } \\
\text { et al. (24) }\end{array}$ \\
\hline 8 & 26 & Male & $\mathrm{IVa}$ & $\begin{array}{l}\text { Erythematous papules on the } \\
\text { trunk, face, upper and lower } \\
\text { extremities, palms, soles, } \\
\text { diarrhea }\end{array}$ & MG & $\begin{array}{l}\text { GvHD-like changes in the skin } \\
\text { biopsy sample }\end{array}$ & $\begin{array}{c}\text { Steroids, } \\
\text { cyclosporine A, } \\
\text { plasmapheresis, } \\
\text { IVIG, mechanical } \\
\text { ventilation (due to } \\
\text { MG crisis) }\end{array}$ & $\begin{array}{l}\text { Mild improvement of skin lesions after } \\
\text { steroids and cyclosporine. Died in } \\
\text { respiratory failure }\end{array}$ & $\begin{array}{l}\text { Gupta } \\
\text { et al. (21) }\end{array}$ \\
\hline 9 & 52 & Male & $\mathrm{IVb}$ & Diarrhea & MG & $\begin{array}{l}\text { GVHD-like phenotype in the } \\
\text { biopsy samples from the } \\
\text { stomach, small intestine and } \\
\text { colon. DIF positive }\end{array}$ & - & $\begin{array}{c}\text { Diarrhea resolved after thymoma resection. } \\
\text { Died of respiratory insufficiency due to MG } \\
\text { crisis }\end{array}$ & $\begin{array}{l}\text { Mais et al. } \\
\text { (22) }\end{array}$ \\
\hline 10 & 48 & Female & IV & Refractory diarrhea, cachexia & MG & $\begin{array}{l}\text { GvHD-like phenotype in the } \\
\text { specimen from the small bowel }\end{array}$ & $\begin{array}{l}\text { Steroids, IVIG, } \\
\text { plasmapheresis, } \\
\text { intubation (for MG } \\
\text { crisis) }\end{array}$ & $\begin{array}{l}\text { No improvement of diarrhea. Died of } \\
\text { respiratory distress due to MG crisis and } \\
\text { K.pneumonia positive pneumonitis and } \\
\text { following DIC }\end{array}$ & \\
\hline 11 & 40 & Female & $\begin{array}{l}\text { B1, recurrent } \\
\text { as B2 }\end{array}$ & $\begin{array}{l}\text { Erythroderma of the trunk, } \\
\text { lower and upper extremities }\end{array}$ & MG & $\begin{array}{l}\text { GvHD-like changes in the skin } \\
\text { biopsy sample }\end{array}$ & $\begin{array}{l}\text { Steroids, } \\
\text { tacrolimus, } \\
\text { cyclosporine A }\end{array}$ & $\begin{array}{l}\text { Mild improvement of skin lesions after } 2 \text { mo. } \\
\text { on steroids and cyclosporine A. While } \\
\text { decreasing steroids doses erythroderma } \\
\text { exacerbation and MG crisis. Died in } \\
\text { respiratory failure and sepsis }\end{array}$ & $\begin{array}{l}\text { Nakagiri } \\
\text { et al. (33) }\end{array}$ \\
\hline 12 & 20 & Male & B1, recurrent & Diarrhea & - & $\begin{array}{l}\text { GvHD-like changes in colonic } \\
\text { biopsy specimen along first } \\
\text { time diagnosis of thymoma }\end{array}$ & $\begin{array}{l}\text { Steroids, } \\
\text { cyclosporine A }\end{array}$ & $\begin{array}{l}\text { Diarrhea resolved multiple times } \\
\text { concomitantly with thymoma remission }\end{array}$ & $\begin{array}{l}\text { Offerhaus } \\
\text { et al. (32) }\end{array}$ \\
\hline
\end{tabular}


13 39 Female

$\mathrm{AB}$

Skin lesions, abnormal LFTs, diarrhea

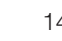

$$
61
$$

Male

$A B$, recurrent

\section{No}

15 data

Early Female recurrent
$50 \mathrm{~s}$

1650

Widespread pruritic, erythematous lesions on the face, trunk, upper and lower extremities

Erythroderma of the face, trunk, $\begin{array}{cc}\text { recurrent } & \begin{array}{c}\text { upper and lower extremities, } \\ \text { abnormal LFTs }\end{array} \\ \text { disseminated } & \text { Pruritic erythema distributed }\end{array}$ $\begin{array}{cc}\text { recurrent } & \begin{array}{c}\text { upper and lower extremities } \\ \text { abnormal LFTs }\end{array} \\ \text { disseminated } & \text { Pruritic erythema distributed }\end{array}$ over the face, trunk, upper and lower extremities

Psoriasiform erythroderma, diarrhea, abnormal LFTs

Erythroderma

Generalized psoriasiform erythroderma and oral mucosa erosions, abnormal LFTs

\section{Erythema involving the face,} trunk, upper and lower

$$
\text { extremities }
$$

$2250 \quad$ Female B1, recurrent Erythematous pruritic lesions on the trunk, upper and lower extremities, abnormal LFTs

$23 \quad 32$ Male B2, recurrent Scaly annular erythema of the trunk developing into erythroderma

$2458 \quad$ Male B3, IVa $\quad$ Pruritic eruptions

Erythemous eruptions
Sjögren's syndrome, PRCA, autoimmune thrombocytopenia

Diarrhea

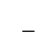

$M G$

MG

MG with multiple crisis

MG, cardiomyopath, opportunistic infections

MG, PRCA

Diagnosis

TAMA treatment

Prognosis

Reference

and concomitantly with its

recurrence 2 years after.

GvHD-like colitis and

Cyclosporine A, in skin and liver biopsy

$$
\text { samples }
$$

terocolitis

GvHD-like changes in the skin biopsy sample

Steroids, PUVA, mycophenolate mofetil

GVHD-like changes in the skin Steroids, tacrolimus biopsy sample

$$
\text { DIF negative }
$$

Steroids,

GVHD-like changes in the skin cyclosporine A, NBbiopsy sample

$$
\text { UVB }
$$

GVHD-like changes in the skin biopsy sample

GvHD-like changes in the skin biopsy sample

GvHD-like changes in the skin biopsy sample

GvHD-like changes in the skin biopsy sample

GvHD-like changes in the skin biopsy sample

GvHD-like changes in the skin Steroids, NB-UVB biopsy sample

GvHD-like changes in the skin biopsy sample

GvHD-like changes in the skin biopsy sample

\section{Steroids} cyclosporine $A$ tacrolimus

Steroids, tacrolimus, ambenonium Steroids

Topical steroids

Steroids

teroids, NB-UVB

Steroids, cyclosporine A phototherapy Steroids
Died of respiratory insufficiency

Skin lesions improving on steroids and further after adding PUVA

Gishen et al. (28)

Several MG crisis requiring mechanical ventilation, thymoma regression on $\mathrm{CHT}$ entailed improvement of skin lesions. Steroids and cyclosporine A with no impact on skin lesions. Good response to steroids +NB-UVB. Died of aspergillosis 5 month after TAMA diagnosis

Skin lesions improved after 2 mo. of steroid Hanafusa therapy, but reappeared after steroids et al. (20) discontinuation. Died of sepsis 5 mo. after

$$
\text { TAMA diagnosis }
$$

Improved skin condition on oral and topical steroids, recurred after treatment withdrawal. Died 3y after TAMA diagnosis of pneumonia Skin lesions resolved on steroids, recurred after steroid withdrawal. Treatment was discontinued after massive progression of thymoma

Skin lesions resolved after radical thymoma resection

Died of respiratory insufficiency due to MG

$$
\text { crisis }
$$

Warren

No improvement of skin condition on steroids. Skin lesions responsive to NBUVB. Died of sepsis.

Partial improvement on steroids and phototherapy. Died suddenly due to cardiac arrest

Skin lesions dissolved on steroids. Died of "disturbance of consciousness" 
Pt Age at Gender

no. diagn.

Thymoma

Clinical symptoms

$26 \quad 61$ Male disseminated Recurrent oral mucosal and lip erosions, erythematous, scaling nonpruriting plaques of the trunk, upper and lower

$$
\text { extremities }
$$
Scaly erythema, red papules
across the trunk, upper and lower extremities evolving into erythema, oral mucosa erosions

Generalized red keratotic papules tended to coalesce into

$$
\text { plaques }
$$

Skin erythema, scaly eruptions of the trunk, face, lower

$$
\text { extremities }
$$

$\begin{array}{llll}31 & \text { Female } & \text { B2 } & \begin{array}{c}\text { Pruritic scaly erythema on lower } \\ \text { extremities that progressed to }\end{array}\end{array}$

$$
\text { cover whole body }
$$

3268 Female B1, locally Erythematous, scaly papules of advanced the face, buttocks, distal parts of upper extremities, oral mucosa erosions/lichenoid-like/ candida-like changes

\section{Other thymoma}

associated

autoimmunities

\section{Diagnosis TAMA treatment}

Prognosis

DIF negative

GvHD-like changes in the skin biopsy sample

Steroids,

azathioprine

DIF positive, IIF negative, antidesmoglein 1 and 3 ,

envoplakin, periplakin negative.

GvHD-like changes in the skin

$$
\text { biopsy sample }
$$$$
\text { IIF negative }
$$

GvHD-like changes in the skin biopsy sample

Tacrolimus, steroids, NB-UVB

Steroid, cyclosporine A

GVHD-like changes in the skin biopsy sample, unspecific features in the liver biopsy, could not rule out GvHD-like phenotype

MG GvHD-like changes in the skin biopsy sample

Hypogammaglobulinemia, GvHD-like changes in the skin Good syndrome biopsy sample

\section{$M G$}

GvHD-like changes of the skin and oral mucosa biopsy samples
Topical steroids, oral retinoid, NBUVB

Steroids, tacrolimus, IVIG

Died due to general deterioration

Mizutani et al. (15)

Steroids

Steroids
No improvement of oral mucositis on

steroids and azathioprine, skin lesions improved on steroids.

Good response of oral mucosa erosions to steroids. Skin condition improvement over steroids + NB-UVB

Skin condition initially improved in steroids, recurred after steroids dose tapering. Cyclosporin A with no impact on skin lesions. Died of progressive multifocal leukoencephalopathy (positive JC virus in CSF)
Improvement of the skin condition on high dose steroids

No improvement despite topical steroids with oral retinoid. NB-UVB with no impact. Skin condition improved after retinoid withdrawal. Patient alive 3 years after.

No improvement of skin and oral mucosa Presented condition along with thymoma remiscion nor on steroids. Patient stable and alive 3 years after TAMA onset.

PousaMartinez et al. (26)

Fukushima et al. (23) case
Hung et al.

(18)

Yatsuzuka et al. (29)

Muramatsu et al. (36) 
PRCA were reported, no reports on TAMA nor PAMS). Nevertheless, an astonishing $47.1 \%$ objective response rate (ORR) was reported in a study of 17 patients with stage II-IVb thymomas to whom corticosteroids were administered prior to thymectomy. Aforementioned study showed 100\% ORR in a WHO type B1 subgroup, that was also diagnosed in our patient, which may have been caused by apoptosis of immature doublepositive CD4+CD8+ lymphocytes triggered by corticosteroids. However, the study also noted a reduction of the TUNEL-stained epithelial component of thymomas following steroid treatment, implicating a more complex relationship between corticosteroid therapy, tumor cellular composition and ORR (55).

The described patient demonstrates two extremely rare phenomena that can accompany thymomas: TAMA and spectacular tumor remission on corticosteroids. Moreover, TAMA presentation in this case was unprecedented due to its GvHD-like oral mucosa involvement that required additional differential diagnosis and exclusion of PAMS. Hence, we suggest that GvHDlike mucositis should be placed in the spectrum of TAMA.

\section{DATA AVAILABILITY STATEMENT}

The original contributions presented in the study are included in the article/Supplementary Material. Further inquiries can be directed to the corresponding author.

\section{ETHICS STATEMENT}

Ethical review and approval was not required for the study on human participants in accordance with the local legislation and

\section{REFERENCES}

1. Engels EA. Epidemiology of Thymoma and Associated Malignancies. J Thorac Oncol 2010 (2010) 5(3):379-90. doi: 10.1097/JTO.0b013e3181f1f62d

2. Padda SK, Yao X, Antonicelli A, Riess JW, Shang Y, Shrager JB, et al. Paraneoplastic Syndromes and Thymic Malignancies: An Examination of the International Thymic Malignancy Interest Group Retrospective Database Sukhmani. J Thorac Oncol (2018) 13(3):436-46. doi: 10.1016/j.jtho.2017.11.118

3. Slavik T, Potgieter FM, Brittain D. Thymoma-Associated Multiorgan Autoimmunity With Exclusive Gastrointestinal Tract Involvement: Case Report and Review of the Literature. Virchows Arch (2018) 473:121-5. doi: 10.1007/s00428-018-2304-6

4. Liu R, Dar R, Tay KY, Nicolle MW, Inculet RI. Thymoma-Associated Myasthenia Gravis in a Young Adult With Development of Paraneoplastic Limbic Encephalitis and Systemic Lupus Erythematosus Post- Thymectomy: A Case Report. Cureus (2018) 10:1-6. doi: 10.7759/cureus.3581

5. Gong L, Zhang P, Liu X, Fang M. Case Report a Rare Thymoma Case With Seven Paraneoplastic Syndromes. Int J Clin Exp Med (2015) 8(10):19517-23.

6. Yung J, Thien T, Chih M, Kang Y, Keong C, Min S, et al. ThymomaAssociated Myasthenia Gravis and LGI1-Encephalitis, With Nephrotic Syndrome Post-Thymectomy. J Neuroimmunol [Internet] (2018) 15:1-3. doi: 10.1016/j.jneuroim.2018.01.011

7. Gastaldi M, De RA, Maestri M, Scaranzin S, Guida M, Borrelli P, et al. Acquired Neuromyotonia in Thymoma-Associated Myasthenia Gravis: A Clinical and Serological Study. Eur J Neurol (2019) 26(7):0-3. doi: 10.1111/ ene. 13922 institutional requirements. In accordance with the Declaration of Helsinki, written consent for publication of this case description accompanied by test results and images was obtained from the patient.

\section{AUTHOR CONTRIBUTIONS}

EW, SD-S, RC, and PP designed and revised the manuscript. EW prepared case description and literature review and wrote the manuscript. MP conducted dermatologic evaluation and revised the manuscript. MB conducted histopathology analysis of skin and oral mucosa samples and revised the manuscript. All authors contributed to the article and approved the submitted version.

\section{FUNDING}

The article was supported financially by Medical University of Lodz.

\section{SUPPLEMENTARY MATERIAL}

The Supplementary Material for this article can be found online at: https://www.frontiersin.org/articles/10.3389/fimmu.2021. 584703/full\#supplementary-material

Supplementary Table 1 | Comparison of PAMS and TAMA diagnostic criteria, histopathology, laboratory tests results and treatment.

Supplementary Figure 1 | A timeline of diagnosis and treatment of the patient.

8. Wadhera A, Maverakis E, Mitsiades N, Lara PN, Fung MA, Lynch PJ. Thymoma-Associated Multiorgan Autoimmunity: A Graft-Versus-Host E Like Disease. Am Acad Dermatol (2007) 57:683-9. doi: 10.1016/ j.jaad.2007.02.027

9. Amber KT. Paraneoplastic autoimmune multi- organ syndrome is a distinct entity from traditional pemphigus subtypes. Nat Rev (2018) 4:18012. doi: $10.1038 /$ nrdp. 2018.12

10. Nguyen VT, Ndoye A, Bassler KD, Shultz LD, Shields MC, Ruben BS, et al. Classification, Clinical Manifestations, and Immunopathological Mechanisms of the Epithelial Variant of Paraneoplastic Autoimmune Multiorgan Syndrome: A Reappraisal of Paraneoplastic Pemphigus. Arch Dermatol [Internet] (2001) 137(2):193-206. doi: 10-1001/pubs.Arch Dermatol.-ISSN0003-987x-137-2-dob00057

11. Amber KT. Paraneoplastic Autoimmune Multi-Organ Syndrome is a Distinct Entity From Traditional Pemphigus Subtypes. Nat Rev Dis Prim (2018) 4:18012. doi: $10.1038 / \mathrm{nrdp} .2018 .12$

12. Solimani F, Maglie R, Pollmann R, Schmidt T, Schmidt A, Ishii N, et al. Thymoma-Associated Paraneoplastic Autoimmune Multiorgan Syndrome From Pemphigus to Lichenoid Dermatitis. Front Immunol (2019) 10:1-8. doi: 10.3389/fimmu.2019.01413

13. Wang MH, Wong JM, Wang CY. Graft-Versus-Host Disease-Like Syndrome in Malignant Thymoma. Scand J Gastroenterol (2000) 2000:667-70. doi: 10.1080/003655200750023660

14. Mais DD, Mulhall BP, Adolphson KR, Yamamoto K. Thymoma-Associated Autoimmune Enteropathy a Report of Two Cases. Anat Pathol (1999) 112:810-5. doi: 10.1093/ajcp/112.6.810 
15. Fukushima A, Ichimura Y, Obata S, Kinoshita-Ise M, Fujio Y, Takeno M, et al. Thymoma-Associated Multi-Organ Autoimmunity: A Case of Graft-VersusHost Disease-Like Erythroderma Complicated by Good Syndrome Successfully Treated by Thymectomy. J Dermatol (2017) 44(7):830-5. doi: 10.1111/1346-8138.13777

16. Sleijfer S, Kaptein A, Versteegh MIM, Noordhoek V, Snels D, van Tilburg AJP. Full-Blown Graft-Versus-Host Disease Presenting With Skin Manifestations, Jaundice and Diarrhoea: An Unusual Paraneoplastic Phenomenon of a Thymoma. Gastroenterol Hepatol (2003) 15:565-9. doi: 10.1097/ 01.meg.0000059130.68845.2c

17. Warren S, Nehal K, Querfeld C, Wong R, Huang J, Pulitzer M. Graft-VersusHost Disease-Like Erythroderma: A Manifestation of Thymoma-Associated Multiorgan Autoimmunity. J Cutan Pathol (2015) 17(10):1310-4. doi: $10.1111 /$ cup. 12642

18. Pousa-Martinez M, Seoane M, Suarez-Penaranda J, Vazquez-Veiga H. GraftVersus-Hostelike Disease Associated With Thymoma. In: J Am Acad Dermatol (2018) 76:7080. doi: 10.1016/j.jaad.2018.05.609

19. Nakayama M, Itoh M, Kikuchi S, Tanito K, Nakagawa H. ThymomaAssociated Cutaneous Graft-Versus-Host-Like Disease Possibly Treated With Narrow-Band UVB Phototherapy. Eur J Dermatol (2016) 26(2):208-9. doi: $10.1684 /$ ejd.2015.2716

20. Gishen FS, Tookman AJ. An Unusual Case of Malignant Thymoma Associated Graft-Versus-Host Disease. BMJ Case Rep (2009) 2009. doi: 10.1136/bcr.05.2009.1866

21. Yatsuzuka K, Tohyama M, Oda F, Hashimoto T, Sayama K. Case of Thymoma-Associated Cutaneous Graft-Versus-Host Disease-Like Disease Successfully Improved by Narrowband Ultraviolet B Phototherapy. J Dermatol (2017) 45:1-4. doi: 10.1111/1346-8138.14176

22. Shiba K, Fujita Y, Miyazawa H, Muramatsu K, Watanabe M, Nishimura M, et al. Thymoma-Associated Multi-Organ Autoimmunity: Two Cases and a Review of the Literature. J Eur Acad Dermatol Venerol (2017) 31(7):324-6. doi: $10.1111 / j \mathrm{dv} .14108$

23. Sader C, Sharma S, Edwards G. Colitis: An Unusual Association of Malignant Thymoma. Ann Thorac Surg (2002) 73:1947-8. doi: 10.1016/S0003-4975(01) 03505-6

24. Motoishi M, Okamoto K, Kaku R, Sawai S, Hanaoka J. Thymoma-Associated Graft-Versus-Host-Like Disease With Skin Manifestations Improved by Complete Resection of Thymoma. Ann Thorac Surg [Internet] (2015) 100 (3):1078-80. doi: 10.1016/j.athoracsur.2014.10.080

25. Offerhaus GJ, Schipper MEI, Lazenby AJ, Montgomery E, Morsink FHM, Bende RJ, et al. Graft-Versus-Host-Like Disease Complicating Thymoma: Lack of AIRE Expression as a Cause of Non-Hereditary Autoimmunity? Immunol Lett (2007) 114:31-7. doi: 10.1016/j.imlet.2007.08.010

26. Nakagiri T, Okumura $M$, Inoue $M$, Minami $M$, Kiyohara E, Umegaki N, et al. Thymoma-Associated Graft-Versus-Host Disease-Like Erythroderma. J Thorac Oncol [Internet] (2007) 2(12):1130-2. doi: 10.1097/JTO.0b013e 31815ba23a

27. Nagano T, Kotani Y, Kobayashi K, Tomita N, Nakata K, Sakashita A, et al. Chemotherapy Improves Thymoma-Associated Graft-Versus-Host-DiseaseLike Erythroderma. BMJ Case Rep [Internet] (2011) 10:1-4. doi: 10.1136/ bcr.03.2011.3936

28. Murata T, Yamamoto M, Kore-eda S, Azuma T, Kabashima K, Morita K. Reactivation of Herpes Simplex Virus and Cytomegalovirus in a Case of Thymoma-Associated Graft-Versus-Host Disease-Like Erythroderma. Acta Derm Venerol (2013) 93:761-2. doi: 10.2340/00015555-1577

29. Muramatsu K, Fujita Y, Inokuma D, Tsukinaga I, Ito K, Nishiura Y, et al. Cutaneous Manifestations of Thymoma-Associated Multi-Organ Autoimmunity: A Fatal Sign. Acta Derm Venerol (2016) 96):818-9. doi: 10.2340/00015555-2367

30. Mizutani H, Suehiro M, Sakurai T, Masuda K, Katoh N. Case of ThymomaAssociated Multi-Organ Autoimmunity Following Herpes Zoster. J Dermatol (2016) 44:1-2. doi: 10.1111/1346-8138.13704

31. Lowry PW, Myers JD, Geller A, Bostwick DG, Clain JE. Graft-Versus-HostLike Colitis and Malignant Thymoma. Dig Dis Sci (2002) 47(9):1998-2001. doi: 10.1023/A:1019656425332

32. Kornacki S, Hansen C, Lazenby A. Graft-Versus-Host-Like Colitis Associated With Malignant Thymoma. Am J Surg Pathol (1995) 19:224-8. doi: 10.1097/ 00000478-199502000-00011
33. Hung C, Tsai T, Chen J, Hsieh M. Thymoma-Associated Multiorgan Autoimmunity. BMJ (2019) 12:2-5. doi: 10.1136/bcr-2018-229163

34. Holder J, North J, Bourke J, Colloby P, Fletcher A, Graham-Brown R, et al. Thymoma-Associated Cutaneous Graft-Versus-Host-Like Reaction. Clin Exp Dermatol (1997) 22:287-90. doi: 10.1046/j.1365-2230.1997.2750703.x

35. Hanafusa T, Azukizawa H, Kitaba S, Murota H, Umegaki N, Terao M, et al. Diminished Regulatory T Cells in Cutaneous Lesions of Thymoma-Associated Multi-Organ Autoimmunity: A Newly Described Paraneoplastic Autoimmune Disorder With Fatal Clinical Course. Clin Exp Immunol (2011) 166:164-70. doi: 10.1111/j.1365-2249.2011.04472.x

36. Gupta V, Subhadarshani S, Wig N, Khandpur S, Verma K. A Rare GraftVersus-Host Disease-Like Thymoma-Associated Paraneoplastic Autoimmune Multiorgan Syndrome. Australas J Dermatol (2017) 1:1-2. doi: 10.1111/ajd.12590

37. Frew JW, Murrell DF. Current Management Strategies in Paraneoplastic Pemphigus (Paraneoplastic Autoimmune Multiorgan Syndrome). Dermatol Clin [Internet] 2011/08/15 (2011) 29(4):607-12. doi: 10.1016/j.det. 2011.06.016

38. Zhang J, Qiao Q, Chen X, Liu P, Qiu J, Zhao H, et al. Improved Outcomes After Complete Resection of Underlying Tumors for Patients With Paraneoplastic Pemphigus: A Single-Center Experience of 22 Cases. J Cancer Res Clin Oncol [Internet] (2011) 137(2):229-34. doi: 10.1007/ s00432-010-0874-z

39. Yamamoto Y, Iwahori K, Funaki S, Matsumo M, Hirata M, Yoshida T, et al. Immunotherapeutic Potential of CD4 and CD8 Single-Positive T Cells in Thymic Epithelial Tumors. Sci Rep (2020) 10:1-9. doi: 10.1038/s41598-02061053-8

40. Strobel P, Murumagi A, Klein R, Luster M, Lahti M, Krohn K, et al. Deficiency of the Autoimmune Regulator AIRE in Thymomas is Insufficient to Elicit Autoimmune Polyendocrinopathy Syndrome Type 1 (APS-1). J Pathol (2007) 216:399-407. doi: 10.1002/path.2141

41. Wang J, Bu DF, Li T, Zheng R, Zhang BX, Chen XX, et al. Autoantibody Production From a Thymoma and a Follicular Dendritic Cell Sarcoma Associated With Paraneoplastic Pemphigus. Clin Lab Investig (2005) 153:558-64. doi: 10.1111/j.1365-2133.2005.06599.x

42. Walters M, Pittelkow MR, Hasserjian RP, Harris NL, Macon WR, Kurtin PJ, et al. Follicular Dendritic Cell Sarcoma With Indolent T-Lymphoblastic Proliferation is Associated With Paraneoplastic Autoimmune Multiorgan Syndrome. Am J Surg Pathol (2018) 00(00):1-6. doi: 10.1097/PAS. 0000000000001158

43. Memis I, Andreadis D, Apessos I, Georgakopoulou E, Poulopoulos A. Paraneoplastic Autoimmune Multi-Organ Syndrome and Oral Mucosa Involvement: An Intriguing Disorder. Cancer Res Front (2015) 1(3):268-79. doi: $10.17980 / 2015.268$

44. Leger S, Picard D, Ingen-Housz-Oro S, Arnault J-P, Aubin F, Carsuzaa F, et al. Prognostic Factors of Paraneoplastic Pemphigus. Arch Dermatol [Internet]. (2012) 148(10):1165-72. doi: 10.1001/archdermatol.2012.1830

45. Sanz-Bueno J, Cullen D, Zarco C, Vanaclocha F. Paraneoplastic Autoimmune Multiorgan Syndrome (Paraneoplastic Pemphigus) With Unusual Manifestations and Without Detectable Autoantibodies. Indian J Dermatol Venereol Leprol [Internet] (2014) 80(4):328-30. doi: 10.4103/0378-6323.136898

46. Cummins DL, Mimouni D, Tzu J, Owens N, Anhalt GJ, Meyerle JH. Lichenoid Paraneoplastic Pemphigus in the Absence of Detectable Antibodies. J Am Acad Dermatol [Internet] (2007) 56(1):153-9. doi: 10.1016/j.jaad.2006.06.007

47. Schmidt T, Solimani F, Pollmann R, Stein R, Schmidt A, Stulberg I, et al. T(H) 1/T(H)17 Cell Recognition of Desmoglein 3 and Bullous Pemphigoid Antigen 180 in Patients With Lichen Planus. J Allergy Clin Immunol [Internet] 2018/ 04/04 (2018) 142(2):669-72.e7. doi: 10.1016/j.jaci.2018.02.044

48. Posner J, Howieson J, Cvitkovic E. "Disappearnig” Spinal Cord Compression: Oncolytic Effect of Glucocorticoids (and Other Chemotherapeutic Agents) on Epidural Metastases. Ann Neurol (1977) 2:409-13. doi: 10.1002/ ana.410020511

49. Green J, Forman W. Response of Thymoma to Steroids. Chest (1974) 65:1146. doi: 10.1378/chest.65.1.114

50. Termeer A, Visser FJ, Mravunac M. Regression of Invasive Thymoma Following Corticosteroid Therapy. Neth J Med (2001) 58:181-4. doi: 10.1016/S0300-2977(01)00090-0 
51. Fujiwara T, Mizobuchi T, Shibuya K, Hiroshima K, Fujisawa T, Iwai N. Rapid Regression of Stage Ivb Invasive Thymoma Under Palliative Corticosteroid Administration. Gen Thorac Cardiovasc Surg (2007) 55:180-3. doi: 10.1007/ s11748-006-0099-X

52. Fukuda A, Sato Y, Iwatsubo S, Komatsu H, Nishiura R, Fukudome K, et al. Minimal Change Nephrotic Syndrome Complicated With Recurrence of Malignant Thymoma: An Interesting Case With Remission Due to Steroid Therapy of Both Nephrotic Syndrome and Thymoma. Nihon Jinzo Gakkai Shi (2009) 51(2):130-7.

53. Hu E, Levine J. Chemotherapy of Malignant Thymoma. Cancer (1986) 57:1101-4. doi: 10.1002/1097-0142(19860315)57:6<1101::AID-CNCR2820570606>3.0.CO;2-A

54. Mizuno T, Hashimoto T, Yamakawa Y, Niwa H. Masaoka a. a Case of a Small Thymoma Associated With Myasthenia Gravis in Which the Tumor was Reduced by Corticosteroid Therapy. Nihon Kyobu Geka Gakkai Zasshi [Internet] (1992) 40(6):975-7.

55. Barratt S, Puthucheary ZA, Plummeridge M. Complete Regression of a Thymoma to Glucocorticoids, Commenced for Palliation of Symptoms. Eur J CardioThoracic Surg [Internet] (2007) 31(6):1142-3. doi: 10.1016/j.ejcts.2007.02.032

56. Kirkove C, Berghmans J, Noel H, Van de Merckt J. Dramatic Response of Recurrent Invasive Thymoma to High Doses of Corticosteroids. Clin Oncol (1992) 4:64-6. doi: 10.1016/S0936-6555(05)80783-6

57. Soffer L, Gabrilove J, Wolf B. Effects of ACTH on Thymic Masses. Endocr Secrion Med Serv (1952) 12:690-6. doi: 10.1210/jcem-12-6-690
58. Shellito J, Khandekar JD, McKeever WP, Vick NA. Invasive Thymoma Responsive to Oral Corticosteroids. Cancer Treat Rep (1978) 62(9):1397-400.

59. Kobayashi Y, Fujii Y, Motoki Y, Hidefumi S, Haruhiro Y, Hiroshi H, et al. Preoperative Steroid Pulse Therapy for Invasive Thymoma. Cancer (2006) 106:1901-7. doi: 10.1002/cncr.21875

60. Almog C, Pik A, Weisberg D, Herczeg E. Regression of Malignant Thymoma With Metastases After Treatment With Adrenocortical Steroids. Isr J Med Sci (1978) 14(4):476-80.

61. Tiseo M, Monetti F, Ferrarini M, Serrano J, Chiaramondia M, Ardizzoni A. Dramatic Responses to Therapy in Rare Tumors. J Clin Oncol (2005) 23 (7):1578-9. doi: 10.1200/JCO.2005.03.115

Conflict of Interest: The authors declare that the research was conducted in the absence of any commercial or financial relationships that could be construed as a potential conflict of interest.

Copyright (C) 2021 Wrona, Dębska-Szmich, Pastuszka, Braun, Czyżykowski and Potemski. This is an open-access article distributed under the terms of the Creative Commons Attribution License (CC BY). The use, distribution or reproduction in other forums is permitted, provided the original author(s) and the copyright owner(s) are credited and that the original publication in this journal is cited, in accordance with accepted academic practice. No use, distribution or reproduction is permitted which does not comply with these terms. 